\title{
Physical activity and human energy expenditure
}

\author{
Citation for published version (APA):
}

Westerterp, K. R., \& Plasqui, G. (2004). Physical activity and human energy expenditure. Current Opinion in Clinical Nutrition and Metabolic Care, 7(6), 607-613. https://doi.org/10.1097/00075197-20041100000004

Document status and date:

Published: 01/01/2004

DOI:

10.1097/00075197-200411000-00004

Document Version:

Publisher's PDF, also known as Version of record

Document license:

Taverne

\section{Please check the document version of this publication:}

- A submitted manuscript is the version of the article upon submission and before peer-review. There can be important differences between the submitted version and the official published version of record.

People interested in the research are advised to contact the author for the final version of the publication, or visit the DOI to the publisher's website.

- The final author version and the galley proof are versions of the publication after peer review.

- The final published version features the final layout of the paper including the volume, issue and page numbers.

Link to publication

\footnotetext{
General rights rights.

- You may freely distribute the URL identifying the publication in the public portal. please follow below link for the End User Agreement:

www.umlib.nl/taverne-license

Take down policy

If you believe that this document breaches copyright please contact us at:

repository@maastrichtuniversity.nl

providing details and we will investigate your claim.
}

Copyright and moral rights for the publications made accessible in the public portal are retained by the authors and/or other copyright owners and it is a condition of accessing publications that users recognise and abide by the legal requirements associated with these

- Users may download and print one copy of any publication from the public portal for the purpose of private study or research.

- You may not further distribute the material or use it for any profit-making activity or commercial gain

If the publication is distributed under the terms of Article $25 \mathrm{fa}$ of the Dutch Copyright Act, indicated by the "Taverne" license above, 


\section{Physical activity and human energy expenditure Klaas R. Westerterp and Guy Plasqui}

\begin{abstract}
Purpose of review
This is a review on the measurement of physical activity under daily life conditions. The focus is on the doubly labelled water method and accelerometry. Doubly labelled water is a gold standard and the reference for the validation of field methods to assess physical activity. Accelerometry is the most objective and precise technique to assess activity patterns in terms of frequency, duration and intensity. Applications of the two techniques are illustrated with the limits of physical activity and energy expenditure and with activity intensity as a determinant of the physical activity level.
\end{abstract}

\section{Recent findings}

The upper limit of the physical activity index (total energy expenditure as a multiple of basal metabolic rate) of 2.5 , as derived from cross-sectional data, is confirmed by training intervention studies. Exercise training, in which total energy expenditure was measured before and at the end of the training programme, showed no increase in physical activity index when training was combined with an energy restricted diet and in elderly subjects. In children, the distribution of time spent at activities with low and high intensity determines the physical activity index while in adults moderate-intensity activities are the main determinant.

\section{Summary}

In adults, within the normal physical activity index range, the distribution of time spent at activities with low and moderate intensity determines the physical activity level. High-intensity activity does not have much impact on daily energy expenditure. High-intensity activity is not required to increase the activity energy expenditure.

\section{Keywords}

accelerometers, body movement, doubly labelled water, energy expenditure, exercise training, physical activity index

Curr Opin Clin Nutr Metab Care 7:607-613. c) 2004 Lippincott Williams \& Wilkins.

Department of Human Biology, Maastricht University, Maastricht, The Netherlands

Correspondence to Klaas R. Westerterp, Department of Human Biology, Maastricht University, PO Box 616, 6200 MD Maastricht, The Netherlands

Tel: +31 43 3881628; fax: +31 433670976 ;

e-mail: K.Westerterp@HB.Unimaas.NL

Current Opinion in Clinical Nutrition and Metabolic Care 2004, 7:607-613

\section{Abbreviations}

AEE activity induced energy expenditure

BMR basal metabolic rate

PAI physical activity index

TEE total energy expenditure

(C) 2004 Lippincott Williams \& Wilkins 1363-1950

\section{Introduction}

Physical activity can be defined as body movement, produced by skeletal muscles, resulting in energy expenditure [1]. Ideally, physical activity is assessed objectively, over periods long enough to be representative for normal daily life, and with minimal discomfort to the subject. Furthermore, it is important to identify physical activity patterns (frequency, duration, intensity) as well as activity-induced energy expenditure. The doubly labelled water method has become the gold standard for the validation of field methods of assessing physical activity. Accelerometers for movement registration are more and more used to objectively assess physical activity including the activity frequency, duration and intensity, and can be used at a larger scale than the more expensive doubly labelled water method. Here, a review is presented on the methodology to measure activity induced energy expenditure (AEE) with doubly labelled water and on the measurement of physical activity with accelerometers. Subsequently, applications of the two techniques are illustrated with the upper limits of physical activity and energy expenditure levels and with activity intensity as a determinant of the activity level.

\section{Measuring activity induced energy expenditure with doubly labelled water}

About 20 years ago, the doubly labelled water method was introduced for human use [2]. The principle of the method is that after a loading dose of water labelled with the stable isotopes of deuterium and ${ }^{18} \mathrm{O}$, deuterium is eliminated as water, while ${ }^{18} \mathrm{O}$ is eliminated as both water and carbon dioxide. The difference between the two elimination rates is therefore a measure of carbon dioxide production (Fig. 1). The deuterium equilibrates throughout the body's water pool, and the ${ }^{18} \mathrm{O}$ equilibrates in both the water and the bicarbonate pool. The bicarbonate pool consists largely of dissolved carbon dioxide, which is an end product of metabolism and passes in the blood stream to the lungs for excretion. The rate constants for the disappearance of the two isotopes from the body are measured by mass spectrometric analysis of samples of a body fluid: blood, saliva or urine.

The method was developed after the discovery in 1949 that the oxygen atoms in the body water and bicarbonate pools are in equilibrium [3]. The technique was initially used for studying energy metabolism of small animals in the wild. The investigator would capture animals, administer the dose of labelled water, release the animals 
Figure 1. Principle of the doubly labelled water method

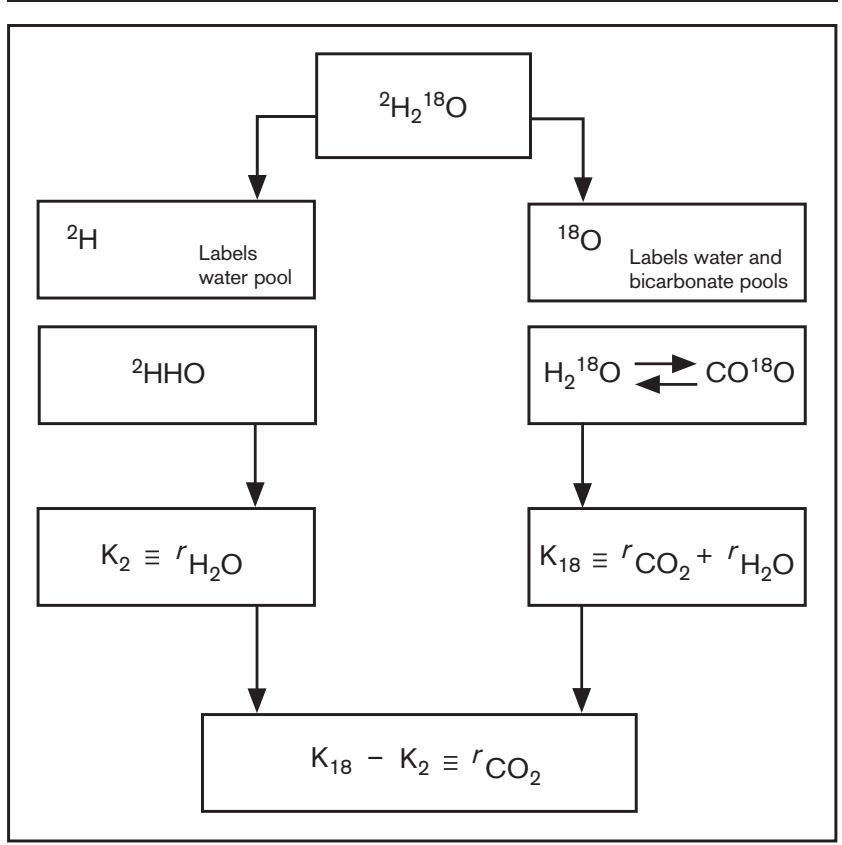

Carbon dioxide production $\left(r_{\mathrm{CO} 2}\right)$ is measured from the elimination rates of ${ }^{18} \mathrm{O}$ and deuterium $\left({ }^{2} \mathrm{H}\right)$ after loading with ${ }^{2} \mathrm{H}_{2}{ }^{18} \mathrm{O}$.

and then recapture them after an appropriate interval to assess the rate at which the isotopes disappeared from their bodies. One of the first such studies involved measuring the energy cost of a $500 \mathrm{~km}$ flight by trained racing pigeons [4]. It was not until 1982 that the method was first used in humans. The reason for this is that ${ }^{18} \mathrm{O}$ water is expensive and a human requires a much higher dose than does a bird. The isotope is not substantially cheaper now, but isotope ratio mass spectrometers have become so sensitive that the method can now work with smaller doses of isotope. Presently, the method is frequently used in humans in several centres [5].

The method is safe to use in humans as the water is labelled with stable isotopes, ${ }^{18} \mathrm{O}$ and deuterium, in low abundance. Both ${ }^{18} \mathrm{O}$ and deuterium are naturally occurring isotopes, which are present in the body prior to the administration of doubly labelled water. As such, tracer studies depend not on measurement of isotopes concentration, but rather on concentrations in excess of natural abundance or background isotope concentrations. The nominal natural abundance of ${ }^{18} \mathrm{O}$ and deuterium is 2000 and $150 \mathrm{ppm}$, respectively. Typical doses of doubly labelled water only produce excess isotope abundances of $200-300$ and $100-150 \mathrm{ppm}$ for ${ }^{18} \mathrm{O}$ and deuterium, respectively.

This method can be used to measure carbon dioxide production and hence energy production in free-living subjects for periods of some days to several weeks. The optimal observation period is one to three biological halflives of the isotopes. The biological half-life is a function of the level of the energy expenditure. Table 1 shows results of measurements in our own laboratory [6] in very young, old and middle-aged, normally active and highly active participants. The minimum observation interval is one times $2.6 \pm 0.4$ days or $3.3 \pm 0.4$ days (about 3 days), in young infants or highly active participants, respectively; the latter were professional cyclists in the Tour de France and Olympic cross-country skiers. The maximum interval is three times 8.9 days or about 4 weeks in elderly (sedentary) participants.

An observation starts by collecting a baseline sample. Then, a weighed isotope dose is administered, usually a mixture of $10 \%{ }^{18} \mathrm{O}$ and $5 \%$ deuterium in, for a $70 \mathrm{~kg}$ adult, $100-150 \mathrm{~cm}^{3}$ water. Subsequently the isotopes equilibrate with the body water and the initial sample is collected. The equilibration time for adults is, depending on body size and metabolic rate, $4-8 \mathrm{~h}$. During equilibration the participant usually does not consume any food or drink. After collecting the initial sample the subject resumes their routine according to the instructions of the experimenter and is asked to collect body water samples (blood, saliva or urine) at regular intervals until the end of the observation period.

Validation studies resulted in an accuracy of $1-3 \%$ and a precision of $2-8 \%$, comparing the method with respirometry [7]. The method has been applied in participants with a wide age range and at different activity levels, from premature infants to elderly persons and from hospitalized patients to athletes in a cycle race. The method requires high precision isotope ratio mass spectrometry working at low levels of isotope enrichment, for the financial reasons mentioned above.

There are different sampling protocols, from a two-point method with a start and end sample to a multi-point method with daily samples throughout the observation period. We prefer a combination of both, taking two independent samples at the start, in the midpoint, and at the end. Thus an independent comparison can be made within one run, calculating carbon dioxide production

Table 1. Biological half-life of ${ }^{18} \mathrm{O}$ in different participant categories

\begin{tabular}{lccc}
\hline Participants & Age (years) & $n$ & $\begin{array}{c}\text { Half-life }{ }^{18} \text { O (days) } \\
\text { Mean } \pm \text { SD }\end{array}$ \\
\hline Infants & $0-1$ & 21 & $2.6 \pm 0.4$ \\
Children & $10-12$ & 29 & $5.1 \pm 0.6$ \\
Adults & $20-40$ & 49 & $7.0 \pm 0.9$ \\
Highly active adults & $20-40$ & 12 & $3.3 \pm 0.4$ \\
Elderly adults & $65-80$ & 17 & $8.9 \pm 1.8$ \\
\hline
\end{tabular}

Adapted with permission [6]. 
from the first samples and the second samples over the first half and the second half of the observation interval $[6,8]$.

The doubly labelled water method gives precise and accurate information on carbon dioxide production. Converting carbon dioxide production to energy expenditure needs information on the energy equivalent of carbon dioxide, which can be calculated with additional information on the substrate mixture being oxidized. One option is the calculation of the energy equivalent from the macronutrient composition of the diet. In energy balance, substrate intake and substrate utilization are assumed to be identical. Alternatively substrate utilization can be measured over a representative interval in a respiration chamber.

Doubly labelled water is an excellent method to measure total energy expenditure (TEE) in unrestrained humans in their normal surroundings over a time period of 1-4 weeks. Subsequently, physical activity can be expressed in terms of energy expenditure by combination with a measurement of basal metabolic rate (BMR) by a ventilated hood. Then, physical activity can be calculated as the AEE (1):

$$
\mathrm{AEE}=0.9 \times \mathrm{TEE}-\mathrm{BMR}
$$

or as the physical activity index (PAI) (2):

$$
\mathrm{PAI}=\mathrm{TEE} \div \mathrm{BMR}
$$

The calculations assume that the third component of TEE, diet induced energy expenditure, is a constant fraction of $10 \%$ of TEE in persons consuming an average mixed diet that meets energy requirements $\left[9^{\circ}\right]$.

Since the doubly labelled water technique is expensive, this method is only applicable for small study populations. Furthermore, this technique provides an accurate measure of TEE but no information on physical activity patterns in terms of frequency, duration and intensity is available. Therefore, several other techniques for the measurement of physical activity in the field have been developed [10]. Here, accelerometry will be described in further detail.

\section{Measuring physical activity with accelerometers}

Accelerometers are electronic motion sensors that consist of piezoresistive or piezo-electric sensors. Piezoresistive accelerometers require an external power source and respond to a constant acceleration such as gravity also. Piezo-electric sensors do not respond to constant acceleration and their major advantage is that no battery power is required, except for data-storage, resulting in a considerable reduction in the size and weight of the device.

Over the past decades, advances in technology have resulted in the development of small uni-axial and triaxial accelerometers for movement registration with a data storage capacity of several days or weeks. Uni-axial accelerometers measure accelerations in one direction, usually mounted in the vertical plane. Tri-axial accelerometers measure accelerations in the anterior-posterior, medio-lateral and vertical directions. For a wide range of different activities, tri-axial accelerometers provide more information and show a better relation with AEE than uni-axial devices [11]. A number of uniaxial accelerometers - CSA (Computer Science and Applications Inc, Shalimar, Florida, USA), currently known as the MTI (Manufacturing Technology Inc, Fort Walton Beach, Florida, USA), Caltrac (Hemokinetics, Madison, Wisconsin, USA) and Lifecorder (Suzuken Co. Ltd, Nagoya, Japan) - and tri-axial accelerometers - Mini Motionlogger actigraph (Ambulatory monitoring Inc, Ardsley, New York, USA), TritracR3 D (Hemokinetics, Madison, Wisconsin, USA) and Physilog (BioAGM, Switzerland) - are currently available. Additionally, about 15 years ago, a tri-axial accelerometer for movement registration, Tracmor (Philips Research, Eindhoven, The Netherlands) was developed at our department. The current, not yet commercially available, Tracmor consists of three separate uni-axial piezo-electric accelerometers, measures $71 \times 26 \times 7 \mathrm{~mm}$ and weighs $22 \mathrm{~g}$ with battery included. Battery power and storage capacity allow continuous data acquisition for periods of at least 3 weeks after which data can be downloaded into a computer.

To test the validity of accelerometers for movement registration, energy expenditure as measured with indirect calorimetry is used as a reference. Thus, many accelerometers have been tested under laboratory conditions during standardized activities [11-16], in field settings against portable calorimeters [17] or in the controlled environment of a whole room calorimeter [1820]. Most accelerometers show good to very good correlation $(r, 0.74-0.95)$ with energy expenditure during walking and running on a treadmill or with other defined activities [11-14,16]. An increasing number of accelerometers have also been validated against doubly labelled water under unconfined conditions in daily life $\left[21^{\bullet \bullet}, 22\right.$ 29]. Correlation between accelerometer output and doubly labelled water derived energy expenditure measures, such as AEE or TEE are often poor and mainly determined by the subject's characteristics such as body mass, age, sex and height [23-25]. Significant correlation between activity counts and PAI, TEE and 
AEE were found for the CSA accelerometer $\left[21^{\bullet}, 22\right]$ and the various models of the Tracmor. So far, of all the accelerometers tested, the Tracmor seems to correlate best with doubly labelled water derived energy expenditure measures with correlation between PAI and activity counts of 0.73 in healthy young adults [26], 0.78 in elderly persons [27] and 0.79 in children [28] and between TEE, corrected for BMR, and activity counts of 0.95 [29].

\section{Upper limits of daily physical activity and energy expenditure}

The most variable component of total energy expenditure is activity induced energy expenditure. AEE sets the upper limit of TEE, for which diet induced energy expenditure can be assumed to be a constant fraction of $10 \%$ of TEE and BMR is determined by body size. Interestingly, there is a narrow distribution of the PAI of subjects. Black et al. [30] suggested earlier that there are boundaries for activity levels within the general population. They suggested a PAI range of 1.2-2.5 for 'sustainable lifestyles'. At PAI values around 2.5 subjects indeed have problems in maintaining energy balance [31]. Only in exceptional groups like endurance athletes, higher PAI values are reached while body weight is maintained. Figure 2 shows the frequency distribution of the PAI for participants measured with doubly labelled water in our laboratory, excluding those with the following characteristics: age under 20 years, had

Figure 2. Frequency distribution of the physical activity index

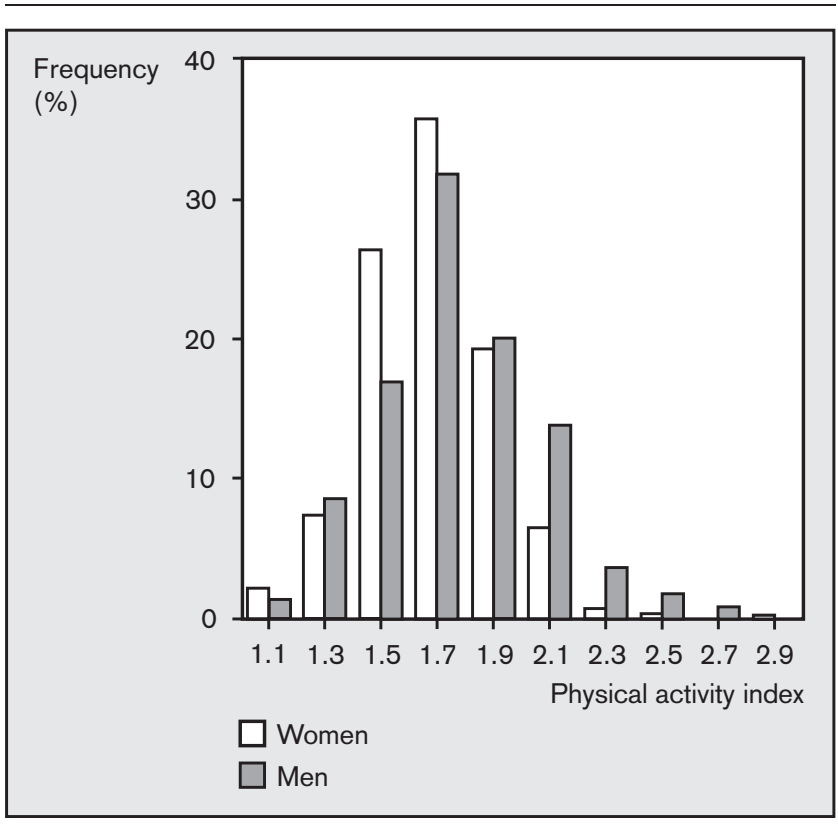

The physical activity index is the total energy expenditure as a multiple of basal metabolic rate. Frequencies are shown for women $(n=226)$ and men $(n=288)$. received an intervention in energy intake, had received an intervention in physical activity including athletic performance, pregnancy, lactation or disease. Data are presented separately for women and for men and show a similar distribution independent of sex. The limits coincide with the range of 1.2-2.5 defined by Black et al. [30].

Training studies of sedentary participants also give confirmation for the upper limit of PAI in the general population at a value of 2.5. Table 2 [32-38] presents data from studies in which the PAI, as assessed with doubly labelled water, was measured before and at the end of a training programme. We could trace eight studies with a diversity of training interventions including jogging, cycling and resistance training. Participants were of normal weight or obese, one study was in children, four were in young adults and three in the elderly. Mean PAI at the start of the intervention ranged from lower values of 1.45 and 1.51 in elderly subjects to values for moderate activity of 1.76 and 1.77 in children and young adults. At the end of the training programme, the highest values of 2.04 and 2.08 were reached in children and young adults as well. No study reported PAI values over 2.5. Three of the training intervention studies reported no effect of training on the PAI; in one study training was combined with energy restriction while the other two studies were in elderly participants.

Training does not have the expected effect on energy expenditure when food intake is not ad libitum. A clear example is that the addition of exercise to an energyrestricted diet results in little further weight loss [39,40]. Weight loss is not different for groups undergoing dietary restriction and dietary restriction plus exercise. The latter implicates that the direct cost of the exercise training is compensated by a reduction of activity associated energy expenditure outside the training sessions. Evidence for the fact that energy restriction negatively affects physical activity also comes from a study of energy restriction per se on physical activity. Velthuis-te Wierik et al. [41] observed the effect of a moderately energy restricted diet on energy metabolism in non-obese men (BMI, $24.9 \pm 1.9 \mathrm{~kg} / \mathrm{m}^{2}$ ). For 10 weeks the men received a diet with $67 \%$ of their measured TEE during weight maintenance. The consequent weight loss was $7.4 \pm 1.7 \mathrm{~kg}$ and the PAI went down from $1.85 \pm 0.37$ to $1.65 \pm 0.29(P=0.06)$; so, there was a tendency for a reduction of physical activity by reducing energy intake.

Physical activity declines with age. Black et al. [30] concluded from an analysis of 574 doubly labelled water measurements that the physical activity level for females is fairly constant between 13 and 64 years, and lower at 
Table 2. Measurements of the physical activity index, total energy expenditure as a multiple of basal metabolic rate, before and at the end of a training programme

\begin{tabular}{|c|c|c|c|c|c|c|}
\hline Training programme & $n$ & Age (years) & BMI $\left(\mathrm{kg} / \mathrm{m}^{2}\right)$ & PAl before & $\mathrm{PAl}_{\text {after }}$ & Reference \\
\hline 9 weeks of jogging for $\leqslant 1 \mathrm{~h} /$ day & 5 & $30 \pm 3$ & $22.4 \pm 2.2$ & $1.58 \pm 0.11$ & $1.99 \pm 0.31^{*}$ & [32] \\
\hline 4 weeks of cycling five times for $1 \mathrm{~h} /$ day & 10 & $11+1$ & $23.9+2.0$ & $1.77+0.15$ & $2.04+0.15^{\star *}$ & [33] \\
\hline 8 weeks of cycling three sessions per week & 11 & $66 \pm 6$ & $24.5 \pm 2.6$ & 1.51 & $1.40, \mathrm{NS}$ & [34] \\
\hline 40 weeks of jogging for up to $50 \mathrm{~km} /$ week & 13 & $37 \pm 3$ & $22.5 \pm 1.6$ & $1.68 \pm 0.18$ & $2.08 \pm 0.17^{\star \star}$ & [35] \\
\hline 8 weeks energy restriction, $4.5 \mathrm{~h} /$ week exercise training & 10 & $39 \pm 5$ & $32.4 \pm 1.3$ & $1.72 \pm 0.07$ & $1.75 \pm 0.10, \mathrm{NS}$ & [36] \\
\hline 18 weeks of weight training for $2 \mathrm{~h} /$ week & 12 & $33 \pm 6$ & $23.6 \pm 1.7$ & $1.76 \pm 0.14$ & $1.92 \pm 0.18^{\star \star}$ & [37] \\
\hline 26 weeks of resistance training for $2.3 \mathrm{~h} /$ week & 15 & $67 \pm 4$ & $24.8 \pm 3.9$ & $1 . \overline{45}$ & 1.53 & [38] \\
\hline 12 weeks of resistance training for $2 \mathrm{~h} /$ week & 22 & $61 \pm 6$ & $27.5 \pm 4.9$ & $1.67 \pm 0.11$ & $1.65 \pm 0.09, \mathrm{NS}$ & [27] \\
\hline
\end{tabular}

PAl, physical activity index. ${ }^{*}<0.05$; ${ }^{* \star} P<0.01$ for difference with before training programme.

younger and older ages. For males physical activity rises to a peak at 18-29 years and declines thereafter. Starling et al. [42] reported a physical activity level of $1.68 \pm 0.28$ in a group of nearly 100 subjects, $69 \pm 8$ years of age, with no significant difference between women and men. Westerterp and Meijer [43] reported a physical activity level of $1.76 \pm 0.20$ in 20-34-year-old subjects, $1.79 \pm 0.25$ for a $35-49$-year-old group (no difference), $1.62 \pm 0.26$ for a $60-74$-year-old group (lower, $P<0.001$ ), and $1.31 \pm 0.24$ for 75 -year-olds and those older (lower, $P<0.0001)$. There seems to be a gradual decline with age, starting at about age 60 years and getting more pronounced after age 80 years. A physical activity level of 1.67 denotes an activity associated energy expenditure of $30 \%$ of total energy expenditure. Thus, on average, subjects of 65 years and over spent less than $30 \%$ of daily energy expenditure on physical activity. Subjects of over 80 years, generally have an extremely low level of physical activity, well below the level of 1.5 as defined for sedentary adults [44]. It is intriguing to observe that the physical activity level of younger persons was modified with exercise training while exercise training had no effect in older people.

\section{Activity intensity as a determinant of the activity energy expenditure}

A low physical activity level is an important characteristic of the current lifestyle. Combined observations of the activity pattern with accelerometers and simultaneously doubly labelled water determined PAI values show the determinants of PAI [45]. We defined activities in three clearly distinct intensity categories: low represents lying, sitting and standing, moderate includes walking, and high includes household activities, exercise and sports. Thus, it was shown that for young adults within the normal PAI range, the distribution of time spent at activities with low and moderate intensity determines the activity level, and high-intensity activity does not have much impact [45]. A later study [46] showed that the reduction in AEE in elderly persons could be explained by a shift from spending more time on lowintensity activities instead of moderate- and highintensity activities. Elderly subjects spent approximately
$17 \%$ more of their time on low-intensity activities than younger adults. In children, PAI showed an inverse relation with the time spent on low-intensity activities and a positive relation with the percentage of time spent on high-intensity activities [47]. Abbott and Davies [48] observed that children spending more time in highintensity activity had a lower percentage body fat while moderate-intensity activity was not correlated with measures of body composition.

Recommendations to increase the amount of physical activity generally focus on moderate-intensity physical activity. There is a consensus statement: 'The current physical activity guideline for adults of $30 \mathrm{~min}$ of moderate-intensity activity daily, preferably all days of the week, is of importance for limiting health risks for a number of chronic diseases including coronary heart disease and diabetes. However for preventing weight gain or regain this guideline is likely to be insufficient for many individuals in the current environment. There is compelling evidence that prevention of weight regain in formerly obese individuals requires 60-90 minutes of moderate-intensity activity or lesser amounts of vigorous-intensity activity. Although definitive data are lacking, it seems likely that moderate-intensity activity of approximately 45 to 60 minutes per day is required to prevent the transition to overweight or obesity. For children, even more activity time is recommended. A good approach for many individuals to obtain the recommended level of physical activity is to reduce sedentary behaviour by incorporating more incidental and leisure-time activity into the daily routine. Political action is imperative to effect physical and social environmental changes to enable and encourage physical activity. Settings in which these environmental changes can be implemented include the urban and transportation infrastructure, schools, and workplaces' (p. 101) $\left[49^{\bullet \bullet}\right]$.

\section{Discussion}

Measurement of AEE with doubly labelled water has become broadly accepted as the reference method. However, the application is limited by the availability 
and cost of ${ }^{18} \mathrm{O}$-labelled water and by the analysis of samples for ${ }^{18} \mathrm{O}$ and deuterium at low enrichment. The price of ${ }^{18} \mathrm{O}$ water has been increasing by a factor of four over the last 20 years. Increased demand for medical use exceeded production capacity for some time, causing delivery times of a year or more. Recently, the production capacity has increased and prices are stable or slightly decreased. For sample analysis one can best start by getting the samples analysed in a laboratory with an established performance. Speakman [5] presented a very detailed description of the theory and practice of the doubly labelled water method, including addresses of isotope suppliers and analysis facilities.

Nowadays, there is a wide choice of accelerometers for movement registration. However, only very few are properly validated. Of those validated against doubly labelled water, the Tracmor so far shows the best accuracy. Of those commercially available, only the CSA (or MTI) has proven to correlate reasonably with doubly labelled water-derived energy expenditure.

To compare physical AEE or body movement, as measured with doubly labelled water or accelerometry, with a reference value, data require normalization for differences in body size. Basically, there are two options: calculation of PAI or expression of AEE per kilogram body weight. Recently, it was shown that PAI does not fully adjust for differences in body size. In children, the increase in AEE and PAI during growth does not equate to a higher level of physical activity expressed as body movement $\left[50,51^{\bullet \bullet}\right]$. An increase in AEE and PAI was more likely due to an increase in body size or body weight, and therefore these estimates were not the best indicators of the total amount of physical activity in comparisons between groups who differ in body size. The obese have higher energy expenditure for an activity than non-obese participants, especially for weight bearing activities. Obese and normal-weight subjects who differed in body weight by more than $40 \mathrm{~kg}$ did not differ in activity counts obtained during the performance of a standard activity (i.e. walking at $4 \mathrm{~km} / \mathrm{h}$ ), but AEE during this standard activity was significantly higher in the obese group [52]. Additionally, physical activity assessed by accelerometry was significantly lower in the obese group, whereas there was no difference between the obese and normal-weight participants in AEE under free-living conditions. AEE per kilogram body mass has to be similar to allow the same body movement in an obese as in a non-obese subject.

\section{Conclusion}

In conclusion, doubly labelled water is an excellent method to measure total energy expenditure in unrestrained humans in their normal surroundings over a time period of 1-4 weeks. Accelerometers are suitable instruments for larger study populations and for additional information on physical activity patterns in terms of frequency, duration and intensity. However, for many instruments, correlation between accelerometer output and doubly labelled water-derived energy expenditure measures are very poor and mainly determined by subject's characteristics such as body mass, age, sex and height. In the general population, there is an upper limit for total energy expenditure as a multiple of resting energy expenditure of 2.5 , as confirmed by training intervention studies. Recommendations to increase the amount of physical activity should primarily focus on moderate-intensity physical activity.

\section{References and recommended reading}

Papers of particular interest, published within the annual period of review, have been highlighted as:

- of special interest

-. of outstanding interest

1 Caspersen CJ, Powell KE, Christenson GM. Physical activity, exercise, and physical fitness: definitions and distinctions for health-related research. Public Health Rep 1985; 100:126-131.

2 Schoeller DA, van Santen E. Measurement of energy expenditure in humans by doubly labeled water method. J Appl Physiol 1982; 53:955-959.

3 Lifson N, Gordon GB, Visscher MB, Nier AO. The fate of utilized molecular oxygen and the source of the oxygen of respiratory carbon di-oxide, studied with the aid of heavy oxygen. J Biol Chem 1949; 180:803-811.

4 Lefebvre EA. The use of D 2 O 18 for measuring energy metabolism in Columba livia at rest and in flight. The Auk 1964; 81:403-416.

5 Speakman JR. Doubly labelled water, theory and practice. London: Chapman \& Hall; 1997

6 Westerterp KR. Body composition, water turnover and energy turnover assessment with labelled water. Proc Nutr Soc 1999; 58:945-951.

7 Schoeller DA, Hnilicka JM. Reliability of the doubly labeled water method for the measurement of total daily energy expenditure in free-living subjects. J Nutr 1996; 126:348S-354S

8 Westerterp KR, Wouters L, van Marken Lichtenbelt WD. The Maastricht protocol for the measurement of body composition and energy expenditure with labeled water. Obes Res 1995; 3 (Suppl 1):49-57.

9 Westerterp K. Energy metabolism and body composition: general principles. - $\quad$ European Respiratory Monograph 2003; 8:1-10.

The monograph explains general principles of energy metabolism in relation to body size, body composition, behaviour, including food intake and physical activity, and health status.

10 Montoye HJ, Kemper HC, Saris WH, Washburn RA, editors. Measuring physical activity and energy expenditure. Champaign: Human Kinetics; 1996.

11 Bouten CV, Westerterp KR, Verduin M, Janssen JD. Assessment of energy expenditure for physical activity using a triaxial accelerometer. Med Sci Sports Exerc 1994; 26:1516-1523.

12 Montoye HJ, Washburn R, Servais S, et al. Estimation of energy expenditure by a portable accelerometer. Med Sci Sports Exerc 1983; 15:403-407.

13 Nichols JF, Morgan CG, Sarkin JA, et al. Validity, reliability, and calibration of the Tritrac accelerometer as a measure of physical activity. Med Sci Sports Exerc 1999; 31:908-912.

14 Nichols JF, Morgan CG, Chabot LE, et al. Assessment of physical activity with the Computer Science and Applications, Inc., accelerometer: laboratory versus field validation. Res Q Exerc Sport 2000; 71:36-43.

15 Terrier $\mathrm{P}$, Aminian K, Schutz Y. Can accelerometry accurately predict the energy cost of uphill/downhill walking? Ergonomics 2001; 44:48-62.

16 Levine JA, Baukol PA, Westerterp KR. Validation of the Tracmor triaxial accelerometer system for walking. Med Sci Sports Exerc 2001; 33:15931597. 
17 Bassett DR Jr, Ainsworth BE, Swartz AM, et al. Validity of four motion sensors in measuring moderate intensity physical activity. Med Sci Sports Exerc 2000; 32 (9 Suppl):S471-S480.

18 Avons P, Garthwaite P, Davies HL, et al. Approaches to estimating physical activity in the community: calorimetric validation of actometers and heart rate monitoring. Eur J Clin Nutr 1988; 42:185-196.

19 Kumahara $\mathrm{H}$, Schutz $\mathrm{Y}$, Ayabe $\mathrm{M}$, et al. The use of uniaxial accelerometry for the assessment of physical-activity-related energy expenditure: a validation study against whole-body indirect calorimetry. Br J Nutr 2004; 91:235-243.

20 Puyau MR, Adolph AL, Vohra FA, Butte NF. Validation and calibration of physical activity monitors in children. Obes Res 2002; 10:150-157.

21 Masse LC, Fulton JE, Watson KL, et al. Influence of body composition on - physical activity validation studies using doubly labeled water. J Appl Physiol 2004; 96:1357-1364.

This study investigated the influence of two approaches: mathematical transformation and statistical procedures, used to account for body composition, on associations between two measures of physical activity and energy expenditure determined by doubly labelled water.

22 Ekelund U, Sjostrom M, Yngve A, et al. Physical activity assessed by activity monitor and doubly labeled water in children. Med Sci Sports Exerc 2001; 33:275-281.

23 Leenders NY, Sherman WM, Nagaraja HN, Kien CL. Evaluation of methods to assess physical activity in free-living conditions. Med Sci Sports Exerc 2001; 33:1233-1240.

24 Rafamantanantsoa $\mathrm{HH}$, Ebine $\mathrm{N}$, Yoshioka $\mathrm{M}$, et al. Validation of three alternative methods to measure total energy expenditure against the doubly labeled water method for older Japanese men. J Nutr Sci Vitaminol (Tokyo) 2002; 48:517-523.

25 Johnson RK, Russ J, Goran MI. Physical activity related energy expenditure in children by doubly labeled water as compared with the Caltrac accelerometer. Int J Obes Relat Metab Disord 1998; 22:1046-1052.

26 Bouten CV, Verboeket-van de Venne WP, Westerterp KR, et al. Daily physical activity assessment: comparison between movement registration and doubly labeled water. J Appl Physiol 1996; 81:1019-1026.

27 Meijer EP, Goris AH, Wouters L, Westerterp KR. Physical inactivity as a determinant of the physical activity level in the elderly. Int J Obes Relat Metab Disord 2001; 25:935-939.

28 Hoos MB, Plasqui G, Gerver WJ, Westerterp KR. Physical activity level measured by doubly labeled water and accelerometry in children. Eur J Appl Physiol 2003; 89:624-626.

29 Goris $\mathrm{AH}$, Meijer EP, Kester A, Westerterp KR. Use of a triaxial accelerometer to validate reported food intakes. Am J Clin Nutr 2001; 73:549-553.

30 Black AE, Coward WA, Cole TJ, Prentice AM. Human energy expenditure in affluent societies: an analysis of 574 doubly-labelled water measurements. Eur J Clin Nutr 1996; 50:72-92.

31 Westerterp KR. Alterations in energy balance with exercise. Am J Clin Nutr 1998; 68:970S-974S.

32 Bingham SA, Goldberg GR, Coward WA, et al. The effect of exercise and improved physical fitness on basal metabolic rate. Br J Nutr 1989; 61:155173.

33 Blaak EE, Westerterp KR, Bar-Or O, et al. Total energy expenditure and spontaneous activity in relation to training in obese boys. Am J Clin Nutr 1992; 55:777-782.

34 Goran MI, Poehlman ET. Endurance training does not enhance total energy expenditure in healthy elderly persons. Am J Physiol 1992; 263(5 Pt 1):E950E957.
35 Westerterp KR, Meijer GA, Janssen EM, et al. Long-term effect of physical activity on energy balance and body composition. Br J Nutr 1992; 68:21-30.

36 Kempen KP, Saris WH, Westerterp KR. Energy balance during an 8-wk energy-restricted diet with and without exercise in obese women. Am J Clin Nutr 1995; 62:722-729.

37 Van Etten LM, Westerterp KR, Verstappen FT, et al. Effect of an 18-wk weight-training program on energy expenditure and physical activity. J Appl Physiol 1997; 82:298-304.

38 Hunter GR, Wetzstein CJ, Fields DA, et al. Resistance training increases total energy expenditure and free-living physical activity in older adults. J Appl Physiol 2000; 89:977-984.

39 Garrow JS, Summerbell CD. Meta-analysis: effect of exercise, with or without dieting, on the body composition of overweight subjects. Eur J Clin Nutr 1995; 49:1-10.

40 Ballor DL, Poehlman ET. A meta-analysis of the effects of exercise and/or dietary restriction on resting metabolic rate. Eur J Appl Physiol Occup Physiol 1995; 71:535-542.

41 Velthuis-te Wierik EJ, Westerterp KR, van den Berg H. Impact of a moderately energy-restricted diet on energy metabolism and body compostion in non-obese men. Int J Obes Relat Metab Disord 1995; 19:318-324.

42 Starling RD, Toth $\mathrm{MJ}$, Carpenter $\mathrm{WH}$, et al. Energy requirements and physical activity in free-living older women and men: a doubly labeled water study. J Appl Physiol 1998; 85:1063-1069.

43 Westerterp KR, Meijer EP. Physical activity and parameters of aging: a physiological perspective. J Gerontol A Biol Sci Med Sci 2001; 56 (Spec No 2):7-12.

44 World Health Organization. Energy and protein requirements, report of a joint FAO/WHO/UNU expert consultation. Technical Report Series. Geneva: World Health Organization; 1985. Report No.: 724.

45 Westerterp KR. Pattern and intensity of physical activity. Nature 2001; 410:539.

46 Meijer EP. Physical activity and oxidative stress in the elderly. Maastricht: Maastricht University; 2001

47 Hoos MB, Kuipers H, Gerver WJM, Westerterp KR. Physical activity pattern of children assessed by tri-axial accelerometry. Eur J Clin Nutr (in press).

48 Abbott RA, Davies PS. Habitual physical activity and physical activity intensity: their relation to body composition in 5.0-10.5-y-old children. Eur J Clin Nutr 2004; 58:285-291.

49 Saris $\mathrm{WH}$, Blair SN, van Baak MA, et al. How much physical activity is - enough to prevent unhealthy weight gain? Outcome of the IASO 1st Stock Conference and consensus statement Obes Rev 2003; 4:101-114.

This is an evaluation of an expert panel of data from a variety of sources to assess the amounts of physical activity necessary to maintain healthy body weights or reduce unnecessary body fat.

50 Hoos MB, Gerver WJ, Kester AD, Westerterp KR. Physical activity levels in children and adolescents. Int J Obes Relat Metab Disord 2003; 27:605-609.

51 Ekelund U, Yngve A, Brage S, et al. Body movement and physical activity - energy expenditure in children and adolescents: how to adjust for differences in body size and age. Am J Clin Nutr 2004; 79:851-856.

This was a study on whether physical activity expressed as body movement (i.e. accelerometer counts) differs from physical activity energy expenditure as a function of body size and age.

52 Ekelund U, Aman J, Yngve A, et al. Physical activity but not energy expenditure is reduced in obese adolescents: a case-control study. Am J Clin Nutr 2002; 76:935-941. 